\title{
EXPERIÊNCIA ESTÉTICA NO MOVIMENTO HIP-HOP: TENSÕES CONTRA HEGEMONICAS NAS PRÁTICAS DE CONSUMO
}

\author{
Aesthetic Experience In The Movement Hip-Hop: \\ Counter-Hegemonic Tensions In The Consumer Practices \\ Experiencia Estética De Los Movimientos Hip-Hop: \\ Tensiones Contra-Hegemónicas En Las Prácticas De Consumo
}

Camila da Silva Marques

Dra. Pesquisadora Universidade Federal de Santa Maria

camila.markes@yahoo.com.br

Rosane Rosa

Profa. Dra. do Depto de Ciências da Comunicação Universidade Federal de Santa Maria

rosanerosar@gmail.com

\section{Resumo}

O presente artigo tem como objetivo a problematização das relações entre o movimento social hip-hop e suas práticas de consumo de produtos de moda de grandes marcas, entendendo até que ponto esses usos e apropriações fragilizam o real sentido do movimento ou servem como mais uma forma comunicativa de reforço da identidade opositiva da cultura hip-hop. Caminhamos amparados teoricamente pelos Estudos Culturais, por autores oriundos da antropologia do consumo e pelas noções de sujeito, atores sociais e novos movimentos sociais, de Alain Touraine (2009). Constatou-se que os hábitos de consumo das marcas globais se prestam a formação identitária, ao pertencimento e aceitação no e do grupo, mas também ao mercado e a sociedade capitalista.

Palavras-chave: Hip-hop. Práticas de consumo. Contradições.

\begin{abstract}
This article problematize the relationship between hip-hop social movement and the consumption practices of big brand fashion products, understanding the extent to which this consuming empties the real sense of movement or serve as another form of communication strengthening the oppositional identity of hip- hop culture. We walked theoretically supported by Cultural Studies, by authors from the anthropology of consumption and the subject notions of social actors and new social movements, Alain Touraine (2009). It was found that the consumption habits of global brands lend themselves to identity formation, to belonging and acceptance in the group, and also to the market and capitalist society.
\end{abstract}

Key words: Hip-hop. Consumer practices. Contradictions. 


\section{Resumen}

En este artículo se pretende problematizar la relación entre el movimiento social hip-hop y sus prácticas de consumo de productos de la moda, buscando la comprensión de la medida en que estos usos y apropiaciones tienen sentido real para el movimiento o sirven como otra forma comunicativa de refuerzo de la identidad de oposición de la cultura hip-hop. Caminamos en apoyados en la teoría de los estudios culturales, en autores de la antropología del consumo n en las nociones de los actores sociales y de los nuevos movimientos sociales - Alain Touraine (2009). Se constató que los hábitos de consumo de las marcas globales se prestan a la formación identitaria, a la pertenencia y aceptación en el grupo y al grupo, sino también al mercado ya la sociedad capitalista

Palabras clave: Hip-hop. Practicas de consumo. Contradicciones.

\section{INTRODUÇÃO}

Nosso recorte investigativo se dá em torno das relações entre sujeitos pertencentes ao movimento hip-hop e suas práticas de consumo de produtos de moda. É Romero (2012) que faz um percurso investigativo a respeito das transformações que a moda, associada a determinado estilo musical, proporciona na sociedade, tendo como foco a moda hip-hop. Segundo a autora, a moda surgida nos guetos urbanos americanos mudou radicalmente a forma de esses sujeitos consumirem e se mostrarem ao mundo, assim como alterou a forma como a indústria fashion passou a tratar essas tendências. Antes de o rap americano passar a ser comercializado, a moda girava em torno da população branca, e é apenas a partir dele que a indústria da moda passa a reconhecer o poder dos afro-americanos e dos latinos como consumidores/produtores de tendências de moda (Romero, 2010).

A problemática que norteia nossa pesquisa está focada na utilização que os sujeitos pertencentes a um movimento social, no caso, o hip-hop, fazem de produtos de moda de marcas hegemônicas, como Nike e Adidas, marcas muito usadas por sujeitos pertencentes a esse grupo. Nos perguntamos até que ponto um movimento, baseado em uma cultura periférica, formado por sujeitos de classes populares que pretendem se opor ao sistema hegemônico nas mais diversas esferas, não deveria, por questão de coerência ideológica, evitar o uso de marcas de grife, reafirmando, assim, seu caráter opositivo. Destarte, objetivamos problematizar as possíveis tensões que se estabelecem nas interações entre um movimento social como o hip-hop e suas práticas de consumo de produtos de moda, desejando compreender se e de que forma esse consumo, entendido como forma comunicativa (García-Canclini, 1999) fragiliza, fortalece ou complexifica a identidade opositiva da cultura 
hip-hop.

No que se refere às opções metodológicas, salientamos que a pesquisa bibliográfica se mostrou insuficiente na abordagem do recorte escolhido, por se tratar de um objeto genuinamente da cultura urbana e popular. Fez-se necessário então um contato direto entre pesquisador e realidade estudada, através da realização de uma pesquisa de campo com observações exploratórias e entrevistas em profundidade com 4 sujeitos pertencentes ao movimento hip-hop.

Em uma imersão etnográfica, participamos de 1) cinco edições da Batalha dos Bombeiros, promovidas mensalmente pelo COR-AP (Coletivo de Resistência Artística Periférica de Santa Maria) - tendo como "palco" a Praça dos Bombeiros; 2) dois ensaios da primeira escola de dança de rua (break) de Santa Maria; e 3) uma exposição de abertura da loja física e comemoração de aniversário dos 4 anos do site de uma urban shop, que vende produtos para grafitagem e roupas de estilo hip-hop em Santa Maria. Quanto aos entrevistados, são eles: V. E. (professor de break), C. TC. (grafiteiro e dono de loja), J. K. (rapper) e G. R. (skatista).

\section{DESENVOLVIMENTO}

\subsection{Consumo cultural}

O homem é um ser social. [...] precisa de bens para comunicar-se com os outros e para entender o que se passa à sua volta. As duas necessidades são uma só, pois a comunicação só pode ser construída em um sistema estruturado de significados (ISHERWOOD e DOUGLAS, 2006, p. 102).

É essa perspectiva social e comunicacional presente no processo de consumo cultural que norteará nossa reflexão. Isherwood e Douglas (2006, p.8), entendem o consumo como "algo ativo e constante em nosso cotidiano" e afirmam que ele "desempenha um papel central como estruturador de valores que constroem identidades, regulam relações sociais e definem mapas culturais" na sociedade contemporânea. Featherstone (1995, p.121) contribui com essa corrente de pensamento e utiliza a expressão "cultura de consumo" para se referir a uma realidade em que as "mercadorias e seus princípios de estruturação são centrais para a compreensão da sociedade contemporânea", envolvendo um foco na "dimensão cultural da economia" - na qual os bens materiais funcionam também "como 'comunicadores', e não apenas como utilidades". O autor destaca ainda que nessa cultura o indivíduo tem consciência 
de que se comunica por meio dos bens que possui, a exemplo de sua casa, carros, objetos de decoração e também do vestuário.

García-Canclini (1999, p.76) também nos desperta para o fato de que os processos de consumo, hoje, são muito complexos, indo além da relação entre "meios manipuladores e dóceis audiências". Ele reconhece a influência de mediadores, como a família, o bairro e o grupo de trabalho no processo de decodificação, interpretação e reapropriação de mensagens e de produtos. Essas mediações contribuem para o entendimento de "como as mudanças na maneira de consumir alteraram as possibilidades e as formas de exercer a cidadania" (p. 37), principalmente para esse estudo que concebe o hip-hop como um movimento social.

As ideias de Hall (2003) também se mostram extremamente caras, pois o autor traz uma outra visão a respeito dos produtos veiculados pelos meios de comunicação de massa, que pode ser adequada ao processo de consumo, através da articulação da produção, circulação, distribuição/consumo e reprodução - momentos distintos, mas interligados. Para Hall e para a corrente dos estudos culturais, o receptor/consumidor definitivamente é um ser dotado de um "repertório cultural", ao qual recorre no momento de captar, interpretar, assimilar e consumir as mensagens recebidas. Essa concepção esclarece a compreensão de que os movimentos subculturais e contraculturais, como o rock, o punk e o hip-hop funcionaram como uma maneira alternativa encontrada pela juventude de se opor às modas dominantes da época em que surgiram, criando, assim, movimentos com músicas, roupas e ideias originais e revolucionárias, causando uma mudança nas relações entre estrutura social e estilos, modas e comportamentos dominantes provenientes dos meios de comunicação de massa.

Entendemos que a moda, através do vestuário, torna-se uma forma comunicativa capaz de carregar consigo um potencial ideológico e político distante da ideia do vestir como um ato despido de intenções, pois, como diz Barnard (2003, p. 184), "moda e indumentária podem ser usadas para contestar e desafiar as identidades de classe e gênero, assim como as relações de poder e status que acompanham essas identidades". Portanto, o consumo de moda pode também ser considerado como uma prática política, já que através dele as identidades de classe podem ser contestadas, possibilitando, assim, que os sujeitos caminhem em direção à mudanças nas suas circunstâncias e condições sociais.

Mas, no caso em estudo do movimento hip-hop, temos que tentar compreender as tensões entre o consumo de marcas de grifes globais e a ideologia contra hegemônica do movimento. Isso porque, ao aderir às grandes marcas internacionais, estão aderindo ao 
paradigma capitalista onde não há espaço para uma contracultura e uma crítica ao sistema vigente.

\subsection{Apontamentos sobre o movimento social hip-hop}

Para conceituarmos o hip-hop como movimento social, nos baseamos nas noções de Alain Touraine (2009), que em 1968 denominou os movimentos sociais como novos movimentos sociais através de uma sociologia da ação, em que o sujeito se torna ator social, engajado e consciente. Para Touraine, esse sujeito político e coletivo tem como objetivo a busca pela construção da democracia social. Em 1973 (p. 336), o autor define um novo movimento social como "a ação conflitante de agentes de classes sociais lutando pelo controle da ação histórica". Com base em Touraine (2009), Picolotto (2007, p. 162) afirma que "os movimentos sociais devem servir de mediadores entre o sujeito e o estado" estando no centro a questão da construção da democracia e do direito às diferenças. Ou seja, o que está em jogo é o conflito cultural, e não apenas o econômico.

Sobre o conflito cultural no movimento hip-hop cabe explicarmos que, desde seu surgimento, nas décadas de 1960/1970 nos Estados Unidos, o estilo que vem originalmente da música black americana funcionava como símbolo de consciência negra e vinha carregado de uma aura conflitiva social muito forte, com características revolucionárias. Dayrell (2001, p.39) revela que "a matriz do rap e do funk reporta à tradição musical africana, reelaborada na diáspora", e localiza sua origem no soul, "uma feliz junção do rhythm and blues". Trata-se, pois, de uma cultura de remixagem, de estímulo a obras derivadas, mas sempre respeitando e conectando a tradição com a modernidade. O rap, nas palavras de Dayrell, "aparece como um gênero musical que articula a tradição ancestral africana com a moderna tecnologia, produzindo um discurso de denúncia da injustiça e da opressão a partir do seu enraizamento nos guetos negros urbanos" (2001, p. 126). No Brasil, Herschmann (1998, p.76) explica que o surgimento do hip-hop, como manifestação cultural ocorreu atrelado a cultura black da década de 1970. Tinha como características a "verborragia', e os temas de suas composições giram em torno de miséria, violência urbana, racismo e assim por diante" (ibidem, p. 76). Essa forte característica de resistência social encontramos também nas reflexões de Fochi (2007, p. 63), para quem o hip-hop segue uma linha voltada a educação, política, conscientização e reivindicação de direitos: 
O hip-hop é muito mais do que música e dança, muito mais do que pular e requebrar - significado literal da tradução em inglês do termo. Ele busca conscientizar, educar, humanizar, promover, instruir e divertir os moradores da periferia, além de reivindicar direitos e o respeito a esse povo.

A partir dessa perspectiva teórica é possível definir o hip-hop como um movimento social, onde os sujeitos se constroem como atores sociais dentro de uma cultura própria, em que a arte, a pintura, a música, a dança e a rima servem como formas de denúncia e de resistência a um discurso interpretativo dominante e a uma posição desigual na sociedade. Cabe analisarmos se essas características de movimento social sobrevivem à pratica de consumo de grandes e caras marcas de grifes globais fundamentadas no paradigma capitalista.

\subsection{Estética e política: o papel do vestuário na cultura hip-hop}

Rancière (2005, p.11) revê as relações possíveis entre estética e política, entendendo "atos estéticos como configurações da experiência, que ensejam novos modos do sentir e induzem novas formas da subjetividade política". Ao dissertar sobre as artes e manifestações estéticas em geral, compreende os desdobramentos e diferentes modalidades artísticas e musicais como formas pelas quais as artes podem ser percebidas e pensadas também como "formas de inscrição do sentido de comunidade" (2005, p. 18). Nesse cenário de múltiplas manifestações, destaca-se também a relação que o autor faz entre política, identidade, estética e democracia "tais formas revelam-se de saída comprometidas com um certo regime de política, um regime de indeterminação das identidades, de deslegitimação das posições de palavra, de desregulação das partilhas do espaço e do tempo. (RANCIÈRE, 2005, p. 18).

Seguindo a lógica de Rancière (2005), é desnecessário que se perceba a estética sob o viés de uma possível cooptação deformadora, isso porque, segundo o autor, há uma estética primeira no alicerce da política. Como exemplificação dessa visão, reportamo-nos aos movimentos contraculturais-que tiveram início nos anos 1960, liderados por grupos de jovens politicamente ativos que reivindicavam e buscavam um rompimento com os hábitos, pensamentos (e modas) dominantes da época, buscando, assim, um caminho para uma sociedade mais democrática, livre e emancipada. Esses jovens, munidos da vontade de (re) criar seus próprios referenciais culturais, tinham, em sua maioria, movimentos musicais (e suas modas) como fio condutor, a exemplo de hippies e punks, que tem em comum o fato de serem manifestações artísticas, que, através de músicas, poesias, artes plásticas, cinema e também do estilo (roupas, acessórios, cabelos, maquiagens), acabaram criando uma 
identidade visual e potencializando as formas de disseminação de suas ideias. O inconformismo dos jovens com a situação política e social do pós-guerra foi manifestado nos comportamentos, nos gostos e também na aparência do vestuário utilizado por eles.

Apesar dessa trajetória contestatória, nas décadas seguintes até a contemporaneidade, a lógica capitalista se incumbiu de reformular esses referencias, convertendo a resistência em práticas de consumo, como convém ao mercado neoliberal globalizado. Assim, o uso de marcas de grifes hegemônicas foram incorporadas como estratégia de reconhecimento e pertencimento a um grupo, a um mercado e à sociedade capitalista. Isso porque, a sociedade capitalista projetou e projeta o prazer, a realização e aceitação social por meio de bens de consumo luxuosos, prazerosos e prestigiosos. Assim, não é difícil compreender que, no paradigma capitalista, consumo tornou-se sinônimo de liberdade, aceitação e pertencimento.

O caso do vestuário hip-hop, para alguns autores, é um exemplo de como a estética da moda pode funcionar como formas de negociações políticas e contraculturais. Para Arce (1999, p.91), o vestuário específico do movimento hip-hop se soma aos elementos gestuais, à pobreza e à cor da pele, e torna-se assim "marca de adscrição grupal, participando da formação de novos elementos de identificação". Deste modo os sujeitos constroem um sentido de si mesmos, reconhecem-se e são reconhecidos. Bergamo (2007) complementa que o vestuário funciona como um dispositivo que auxilia na expressão da ideologia da cultura hip-hop, e Stevenson (2012, p. 244) reafirma esse pensamento, e diz que "não foi só a linguagem que fez parte do estabelecimento da cultura hip-hop, mas também um código de vestuário dotado de padrões que significavam pertencimento ao grupo". Temos que salientar, porém, que, no caso do consumo de marcas hegemônicas, esse mesmo código carrega o paradigma e o pertencimento a uma sociedade capitalista e hegemônica, evidenciando um traço contraditório em relação à ideologia da cultura hip-hop.

A fim de exemplificar esse tipo de vestuário característico, mas hegemônico, reportamo-nos a Wilson (s/d, p.1), que entende que o look hip-hop é composto por vários elementos:

[...] calças e jaquetas de couro preto, chapéus Fedora pretos ou chapéus Kangol, grandes correntes e, claro, tênis Adidas. [...] O conjunto era muitas vezes completado por um boné de beisebol [...] e por um par de tênis de marca (a Adidas perdeu terreno para a Nike). Chapéus (e às vezes outras peças de roupa) eram usados ao contrário. Uniformes de basquete eram usados sobre camisetas, com jeans tão largos que formavam uma espécie de poça de tecido que só ficava presa ao corpo por estar segura ao topo das botas Timberland ou Lugz. 
Esses exemplos servem como base teórica para discutirmos e entendermos as relações entre sujeitos participantes de um movimento social como o hip-hop com o consumo de marcas de moda, descritas a seguir, com base na pesquisa empírica.

\subsection{Hip-hop e consumo de moda: costuras (empíricas) de uma relação}

É através das falas de C.TC que iniciamos o diálogo a respeito da relação entre movimento social hip-hop e determinadas marcas de moda. É ele quem reforça o entendimento de que algumas marcas são adotadas pelos sujeitos adeptos desse estilo, como Adidas, Nike e Slum, esta última, à venda entre os produtos de sua loja. Para ele, ter uma marca tão representativa desse público é motivo de felicidade e realização, porque, "além de ser um material bom e de qualidade, é $100 \%$ nacional". Sobre a relação com as marcas, explica:

Tu comprar um Nike, mesmo que falsifix (falsificado) tu já tá carregando a ideia do Nike, né? Mas tipo, pô, imagina o cara usando um Croc. Sou do hip-hop rapá, não dá pra usar esse tipo de coisa (risos) (C. TC, 2013).

As falas de C. TC reafirmam a ideia obtida por nós através da pesquisa bibliográfica, documental e de campo, a respeito da relação estreita dos sujeitos do hip-hop com o vestuário, e com algumas grandes marcas hegemônicas de calçado e vestuário. Podemos inferir que tal apego "mesmo que falsifix" remete à uma contradição ideológica: "tá carregando a ideia do Nike". Uma ideia capitalista, hegemônica e globalizada ligada, colada a um movimento cujas muitas letras de músicas sinalizam para uma postura de resistência e contra hegemonia.

Coerente com a sociedade capitalista, o fragmento abaixo reforça o lugar central do consumo e do estilo de roupas grandes, porém de marca, no cotidiano dos integrantes do movimento, a ponto de "acalmar meu lado agressivo".

Eu acho que no início, quando a gente começa a se identifica com a cultura e com o movimento, a gente quer é mostrar mesmo que faz parte daquilo, né? O Projota mesmo tem uma música que fala disso aí, que fala assim: "comprei duas camiseta GG, e a calça mais larga que a loja podia vender, funcionava como um incentivo, mais um motivo pra eu acalmar meu lado agressivo" (C.TC).

Assim como C. TC, G.R concorda que há uma relação forte entre sujeitos do hip-hop e marcas hegemônicas, e acaba admitindo a fragilidade do movimento em manter uma ideologia anti-capitalista e contra hegemônica, uma vez que não resistem às seduções de 
consumo da sociedade capitalista. Assim, mesmo sabendo da utilização de mão de obra escrava no processo produtivo, não vê alternativas, mas assujeitamento: "não tem como fugir":

É que a Nike foi a precursora da utilização da mão de obra escrava na China, hoje em dia todas as marcas usam, fazem isso, marcas de skate mesmo, tá todo mundo com fábrica na China, teve uma marca de Tênis Aes que não botou fábrica na China, que tinha princípios, era uma marca super grande também, e daí veio a falir, porque não acompanhava a concorrência, não tinha condição de concorrer. É, o cara ter ideologias hoje, é bem difícil de se manter, porque a sociedade, o capitalismo, ele invade a vida de todo mundo, não tem como tu fugir, é muito difícil, e tu acaba usando.

Para ele, as grandes marcas e conglomerados de vestuário e de calçados carregam consigo as mazelas do capitalismo, e isso acaba indo contra os princípios resistentes do movimento que, mesmo assim, se adapta a essas mazelas como "todo o mundo". Diante disso, temos que questionar qual a ideologia do movimento hip-hop: onde está sua resistência aos valores da sociedade hegemônica, que contracultura é essa?

A contradição também se faz presente na fala de A V. E. que legitima o paradigma capitalista de liberdade pela via do consumo e não da resistência, defendendo que os sujeitos do hip-hop têm "todo o direito" de aderir à grandes e caras marcas na hora de se vestir. Afirma ainda que a associação entre marginalidade/pobreza e hip-hop já não serve para saciar as relações de consumo de sujeitos adeptos a um movimento. Ele conta que "as próprias marcas que o pessoal do hip-hop usa, como Nike, Adidas e Ecko, são mais caras do que um terno no Tevah, por exemplo".

C. TC é mais taxativo ao reforçar um discurso de cunho capitalista que se pauta na ideia de que as pessoas são livres para escolher o que desejam consumir:

Isso é preconceito ao contrário, né? Acho que o cara tem que ser livre, antes de mais nada, antes de tu querer usar um Croc ou um Adidas tu tem que ser livre, sabe? Tu quer usar, tu usa. É aquela coisa que eu tava falando assim, pô, tu tem que tá à vontade com o jeito que tu anda, sabe?

Pensamos que não se trata de "preconceito ao contrario", mas ausência de resistência ao paradigma capitalista e hegemônico que prega a liberdade pela via do consumo.

No entanto, apesar dessa legitimação às grandes e caras marcas globais, G. R sinaliza que o consumo de marcas alternativas e de cooperativas de vestuário independentes são um caminho para resistir aos apelos dos grandes conglomerados internacionais de vestuário. 
São alternativas legais, se tu puder, por exemplo, o cara que tá do leu lado ali, o cara tá fabricando uma camiseta, o cara lá vende um boné...fortalecer o cara do lado ali, né? Compra lá pra fortalecer o cara e não pra fortalecer os grandes.

Já J. K acredita que os conglomerados como Nike e Adidas não são as únicas marcas fortes no cenário hip-hop, e destaca algumas outras que considera representativas do movimento, como Slum e Confusão. Apesar disso, ele chegou no dia da entrevista usando uma camiseta da marca independente criada por G. R, e nos contou que apoia as marcas autônomas de vestuário.

Hoje em dia existem mais marcas ainda exclusivamente do hip-hop. Eu uso Nike também, tranquilo, mas eu sou totalmente a favor de apoiar marcas independentes. Essa camiseta que eu tô usando da marca N. é daqui (de Santa Maria), e a maioria das minhas camisetas hoje são dessa marca, eu incentivo isso. Eu mesmo já pensei em lançar uma marca. Mas de tênis ainda não lançaram, e acho que só por isso acabo usando Nike e Adidas. Mas com certeza não é isso que vai enfraquecer a ideologia do movimento.

No que se refere ao consumo das marcas globais pelos integrantes do hip-hop, como movimento social, é preciso questionar essa "certeza" de que "não é isso que vai enfraquecer a ideologia do movimento". Se enfraquece não sabemos, mas temos que admitir que é, no mínimo, contraditório a um movimento social reforçar o sistema capitalista por meio do consumo de grandes marcas globais. Por outro lado, o entrevistado evidencia uma disposição para aderir à marcas alternativas, uma vez que já faz uso de marcas locais de vestuário, juntamente com a global da Nike.

\section{CONSIDERAÇÕES}

A problemática que norteou a nossa reflexão voltou-se para as práticas de consumo dos sujeitos pertencentes ao movimento hip-hop no que se refere a produtos de moda de marcas hegemônicas, como Nike e Adidas, entre outras grifes globais. Problematizamos, a partir das entrevistas em profundidade feitas com integrantes do movimento na cidade de Santa Maria, as possíveis contradições ideológicas entre o paradigma capitalista que norteia as marcas consumidas pelo movimento e a ideologia de oposição e resistência ao sistema hegemônico, defendida pelo movimento como raiz identitária por meio do grafite, da dança e 
de muitas letras de músicas.

A análise das entrevistas evidencia uma postura, no mínimo, contraditória dos integrantes do movimento social hip-hop. A prática de consumo, com forte adesão e até ostentação de grandes e caras marcas de grifes globais remete a um processo de retroalimentação onde o movimento hip-hop alimenta e é alimentado pelo sistema capitalista hegemônico. Esses hábitos de consumo das marcas globais se prestam a formação indenitária, ao pertencimento e aceitação no e do grupo, mas também ao mercado e a sociedade capitalista.

Ao contrário do caráter político e contestatório presente na arte e em muitas músicas do hip-hop que o caracterizam como um movimento social, as entrevistas remetem mais a uma "tribo urbana" cuja distinção identitária se dá pela estética e pelos hábitos de consumo, como requer a sociedade hegemônica neoliberal. Maffesoli (2000, p.47), explica as características e significações que norteiam uma tribo urbana:

O denominador comum de todos esses atos mundanos é uma co-presença mais ou menos teatral, que faz aparecer ao outro, que faz parecer diante do outro, que faz parecer diante do outro. Sem isso não há vida social. (...) não tem o cheiro da matilha que se mantem misturando seu próprio suor ao dos outros.

Por outro lado, a iniciativa e o consumo de marcas independentes de vestuário, presentes nas falas de dois entrevistados, se mostram como uma forma de resistência e oposição ao sistema dominante. Há o esforço de fugir da armadilha capitalista, atenuando esse circuito mercadológico que beneficia o hegemônico e vivendo com maior coerência com a identidade de um movimento social que como tal, exige um caráter contestatório que contribua com a transformação da estrutura social vigente. Assim, a alternativa contra hegemônica em relação à moda pode se dar por meio do crescimento e a ampliação de iniciativas independentes que consigam a adesão dos integrantes do movimento.

Portanto, as constatações de nosso estudo vão ao encontro do resultado da pesquisa de Fochi (2007) ao evidenciar que, apesar da maioria dos autores que abordam essa temática adotarem a definição do hip-hop como movimento social, ele também possui características de tribo urbana.

\section{REFERÊNCIAS}

ARCE, José Manuel Valenzuela. Vida de barro duro: cultura popular e juvenil. Rio de Janeiro: 
EDUFRJ, 1999.

BARNARD, Malcolm. Moda e Comunicação. Rio de Janeiro: Rocco, 2003.

BECKER, Howard. Métodos de pesquisa em ciências sociais. São Paulo: Hucitec, 1997.

BERGAMO, Alexandre. A experiência do status: roupa e moda na trama social. São Paulo: UNESP, 2007.

CASTELLS, Manuel. O poder da identidade: a era da informação: economia, sociedade e cultura. São Pulo: Paz e Terra, 1999.

DAYRELL, Juarez. A música entra em cena: o rap e o funk na socialização da juventude em Belo Horizonte. 2001. Tese (Doutorado em Educação) - Universidade de São Paulo, São Paulo, 2001.

ESCOSTEGUY, Ana Carolina; JACKS, Nilda. Comunicação e Recepção. São Paulo: Hacker, 2005.

FEATHERSTONE, Mike. Cultura de consumo e pós-modernismo. São Paulo: Studio Nobel, 1995.

FOCHI, Marcos Alexandre Bazeia. Hip hop brasileiro: tribo urbana ou movimento social? In: Revista FACOM, São Paulo, vol 01, n.17, junho de 2007. Disponível em:

$<$ http://www.faap.br/revista faap/revista facom/facom 17/fochi.pdf> Acesso em: 18 de outubro de 2012.

GARCÍA-CANLINI, Néstor. Consumidores e cidadãos: conflitos multiculturais da globalização. Rio de Janeiro: UFRJ, 1999.

HALL, Stuart. Da diáspora: identidades de mediações culturais. Belo Horizonte: UFMG, 2003.

HERSCHMANN, Micael. (Org.). Abalando os anos 90: funk e hip hop, globalização, violência e estilo cultural. Rio de Janeiro: Rocco, 1998.

O funk e o hip-hop invadem a cena. Rio de Janeiro: UFRJ, 2000.

ISHERWOOD, Baron; DOUGLAS, Mary. O Mundo dos Bens: para uma antropologia do consumo. Rio de Janeiro: UFRJ, 2006.

MAFFESOLI, Michel. As mascaras do corpo. Líbero: revista acadêmica de pós-graduação da faculdade de comunicação social Cásper Líbero, São Paulo, Ano III, Vol.3 N.6, 20. Semestre, 2000.

PICOLOTTO, Everton Lazzaretti.Movimentos Sociais: abordagens clássicas e contemporâneas. Revista Eletrônica de Ciências Sociais, v. 2, n. 2, Rio de Janeiro, 2007.

RANCIÈRE, Jacques. A partilha do sensível: estética e política. São Paulo: Exo/ Editora 34, 2005. ROMERO, Elena. Free Stylin': How Hip Hop Changed the Fashion Industry. Connecticut: Praeger, 2012.

STEVENSON, Nj. Cronologia da moda: de Maria Antonieta a Alexander McQueen. Rio de Janeiro: Zahar, 2012.

TOURAINE, Alain. Iguais e Diferentes: Poderemos viver juntos? Petrópolis, RJ: Vozes, 2009. . Os movimentos sociais. In: FORACCHI, M. M.; MARTINS, J. de S. Sociologia e sociedade. 
Rio de Janeiro: Livros Técnicos e Científicos, 1973.

Pensar Outramente: o discurso interpretativo dominante. Petrópolis, RJ: Vozes, 2009.

\section{Sites:}

WILSON, Tracy. How Stuff Works. Disponível em: 〈http://www.hsw.uol.com.br/>. Acesso em: 25 de fevereiro de 2013.

\section{Entrevistas:}

V. E. Professor de break. Santa Maria, 5 de abril de 2013. Entrevista concedida a autora.

C. TC. Grafiteiro, dono de loja e oficineiro de grafite. Santa Maria, 25 de abril de 2013. Entrevista concedida a autora.

G. R. Estudante de Educação Física e skatista. Santa Maria, 30 de abril de 2013. Entrevista concedida a autora.

J. K. Rapper. Santa Maria, 20 de agosto de 2013. Entrevista concedida a autora.

Original recebido em: 24 de novembro de 2016

Aceito para publicação em: 7 de dezembro de 2017

Camila da Silva Marques

Doutora em Comunicação/Mídia e Identidades Contemporâneas, pela Universidade Federal de Santa Maria, com doutorado sanduíche (PDSE/CAPES) na Universidade Católica Portuguesa - Lisboa. Mestra em Comunicação Midiática, linha Mídia e Identidades Contemporâneas, pela Universidade Federal de Santa Maria (20013). Especialista em Comunicação e Projetos de Mídia pelo Centro Universitário Franciscano (2009). Pesquisadora do Grupo de Pesquisa Comunicação, Gênero e Desigualdades (UFSM/CNPq) e produtora audiovisual.

Rosane Rosa

Doutora em Comunicação e Informação pela Universidade Federal do Rio Grande do Sul (2009), Mestre em Comunicação pela Universidade do Vale do Rio dos Sinos (2000), Especialista em Administração de Marketing (1993). Professora no Departamento de Ciências da Comunicação, do Programa de Pós-graduação em Comunicação e do Programa Tecnologias Educacionais em Rede da Universidade Federal de Santa Maria. Coordenadora do Acordo de Cooperação Internacional entre a Universidade Federal de Santa Maria e a Universidade de Cabo Verde. Coord.do Acordo de Cooperação Internacional entre a UFSM e a Universidade Pedagógica de Moçambique - Projeto Educomunicação Intercultural \CAPES. Profa. Visitante dos Programas de Pós-graduação Design e Multimídia e Jornalismo e Mídias Digitais da Universidade Pedagógica de Moçambique. Integra a Global Alliance for Partnerships on Media and Information Literacy (GAPMIL). Lidera o Grupo de Pesquisa Comunicação, Educação Intercultural e Cidadania (CNPQ) e Coordena o Projeto de Ensino, Pesquisa e Extensão - EDUMIX Editora Aberta. É pesquisadora CAPES e investiga os temas Comunicação, Direitos Humanos, Políticas Sociais, Educomunicação, Alteridade e Cidadania. Pós-doutoranda na Universidade de Coimbra, sob a supervisão do Prof. Boaventura de Souza Santos. 


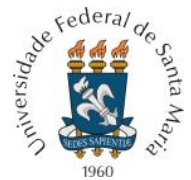

PROGRAMA DE PÓS-GRADUAÇÃO EM COMUNICAÇÃO DA UNIVERSIDADE FEDERAL DE SANTA MARIA

(c) (i)

Esta obra está licenciada sob uma Licença Creative Commons. 